\title{
The effectiveness of two types of adhesive for catching insects in traps
}

\author{
Peter L. Lo ${ }^{1, *}$, Roger Wallis ${ }^{2}$ and David E. Bellamy ${ }^{2}$ \\ ${ }^{1}$ The New Zealand Institute for Plant and Food Research Limited, Private Bag 1401, Havelock \\ North, New Zealand \\ ${ }^{2}$ The New Zealand Institute for Plant and Food Research Limited, 55 Old Mill Road, RD3, \\ Motueka 7198, New Zealand \\ ${ }^{\star}$ Corresponding author: peter.lo@plantandfood.co.nz
}

\begin{abstract}
Sticky traps for monitoring insects use polybutene adhesive (PBA) to entangle insects. This glue is effective but messy to use and an alternative, hot-melt pressure-sensitive adhesive (HMPSA) is available. The effectiveness of these two adhesives was compared for catching pest and beneficial insects, primarily in apples. Various types of trap with either PBA or HMSPA were placed in orchards and vineyards in Hawke's Bay and Nelson. Eight pests from six families, six parasitoids, five predators and one pollinator were commonly recorded. Traps with HMPSA generally caught similar numbers or more of both insect pests and beneficial insects than traps with PBA. Traps with HMPSA performed better for larger insects $(>1.5 \mathrm{~mm})$, whereas those with PBA tended to be more effective for smaller insects. Both types of adhesive were effective for up to 4 weeks. HMPSA was effective for monitoring a range of insect pests and beneficial insects. Compared with PBA, HMPSA was more consistent and much cleaner and easier to use. It is recommended that HMPSA replaces $\mathrm{PBA}$ in traps for monitoring moth pests in the pipfruit industry.
\end{abstract}

Keywords polybutene adhesive, hot-melt pressure-sensitive adhesive, apple, monitoring, integrated fruit production

\section{INTRODUCTION}

Researchers and orchardists use traps to monitor populations of both pest and beneficial insects. Typically, a chemical lure (e.g. pheromone, food odour, or host-plant volatile chemical) is used to attract insects to the trap but specific trap colour and shape may also attract insects. A sticky gluecoated surface on the trap restrains insects that land on it. After a certain time, traps are removed so the catch can be identified and counted.

A common insect trap design used in New Zealand and overseas is the 'delta' trap, made from corflute plastic and named for its triangular cross-sectional shape. The housing protects a pheromone lure placed on a removable card that is coated with polybutene adhesive (PBA, e.g. Tanglefoot ${ }^{\circledast}$ ). PBA has the consistency of a sticky gel and is very effective at catching insects but is also messy to use because the glue is not easily removed from hands without a solvent.

The New Zealand pipfruit industry has approximately 10,000 ha of orchards, $95 \%$ of which grow fruit for export (Anon. 2018). Export orchards operate under either New Zealand Integrated Fruit Production or organic programmes. Both programmes require that two key pests, codling moth (CM, Cydia pomonella) and lightbrown apple moth (LBAM, Epiphyas postvittana), be monitored with pheromone traps and that growers respond to catches above set thresholds by spraying to control populations (Walker et al. 2001). Apple orchards must have one or two traps per hectare for each of these pests, which equates to approximately 9000 
and 5000 traps nationally for CM and LBAM, respectively. These traps are checked weekly from October to March with the sticky cards being changed every 3 weeks. This replacement frequency requires seven to nine card changes/ season and over 100,000 cards/year, which end up in landfills.

Liners coated with hot-melt pressure-sensitive adhesive (HMPSA) have become available for delta traps in the past decade (Hall et al. 2010). This glue is permanently sticky at ambient temperatures and requires only light contact to bond to another substrate.

The primary objective of this study was to determine if HMPSA is a suitable replacement for PBA to monitor CM and LBAM in pipfruit orchards. Secondary objectives were to compare these two adhesives for their effectiveness at catching other pest and beneficial species, and their ease of use. Three other apple pests were included in the study: apple leafcurling midge (ALCM, Dasineura mali), San José scale (SJS, Quadraspidiotus perniciosus) and Froggatt's apple leafhopper (FAL, Edwardsiana froggatti). In addition, we also monitored Oriental fruit moth (OFM, Grapholita molesta), which primarily attacks stonefruit but can also infest pipfruit, citrophilous mealybug (Pseudococcus calceolariae), which infests a range of crops, but is a particular problem on grapes in New Zealand, and the Australian crop mirid (ACM, Sidnia kinbergi), which is a polyphagous pest of vegetables and pasture species (Eyles 1999).

\section{MATERIALS AND METHODS}

Trials were conducted in apple or stonefruit orchards and vineyards in Hawke's Bay and Nelson. Three types of trap were used: (a) threesided delta design from red corflute plastic; (b) two-dimensional white cardboard; and (c) twodimensional yellow cardboard or corflute. Traps contained either PBA or HMPSA (Table 1).

\section{Delta traps}

Delta traps consisted of a three-sided red corflute plastic housing. One of two types of adhesive card was placed in each trap: (i) the industry- standard card, which is an $18 \times 19 \mathrm{~cm}$ piece of corflute with a PBA-coated (Tanglefoot) area of about 17 x $18 \mathrm{~cm}$ (Etec Crop Solutions, Auckland, New Zealand); and (ii) a new type of card, made of waxed cardboard, $17.5 \times 20 \mathrm{~cm}$, with HMPSA spread over $16.5 \times 17.5 \mathrm{~cm}$ (No-Mess Sticky Card $^{\text {tw }}$, AlphaScents Inc., OR, USA). A speciesspecific pheromone lure was placed in the centre of each card to attract one of five pest species: CM, LBAM, OFM, ALCM and citrophilous mealybug.

Delta traps were placed in the field continuously for 6-28 days depending on species and region between January and April 2019. Traps for each species were checked two or four times at intervals of about 1 to 2 weeks. The positions of the two types of adhesive cards were exchanged within each replicate after each visit.

An extra comparison was undertaken for $\mathrm{CM}$ to evaluate cards for their longevity over 4 weeks. The cards were either changed weekly or left unchanged with moths simply removed each week.

\section{White cardboard traps}

Two types of white trap were used: (i) $9.5 \times 30$ $\mathrm{cm}$ cards (Trécé Inc., OK, USA) that were folded crosswise to have approximately $8 \times 12.5 \mathrm{~cm}$ of PBA on each side; or (ii) the AlphaScents HMPSA cards used above. The latter were trimmed to have the same glued dimensions as the Trécé PBA cards. A pheromone is available for SJS and these lures were attached to the white cardboard. These traps were hung in the open, about $1.5 \mathrm{~m}$ above ground, amongst apple trees for 4 consecutive weeks with the cards changed and positions swapped after 2 weeks.

\section{Yellow traps}

Two types of yellow trap were used: (i) an $18 \mathrm{x}$ $19 \mathrm{~cm}$ piece of corflute plastic coated with PBA on one side without an unglued border; or (ii) a yellow $14 \times 20 \mathrm{~cm}$ AlphaScents card with an HMPSA area of $13 \times 16.5 \mathrm{~cm}$. The yellow AlphaScents cards are double-sided but only one side was used, to match the corflute as best as possible given their different sizes. These traps 
Table 1 Summary of the insects monitored and trapping conducted in 2019 during this study.

\begin{tabular}{|c|c|c|c|c|c|c|c|}
\hline Insect & Species & $\begin{array}{l}\text { Body } \\
\text { length } \\
(\mathrm{mm})\end{array}$ & $\begin{array}{l}\text { Trap colour/ } \\
\text { type }\end{array}$ & Crop & Location & $\begin{array}{c}\text { Trapping } \\
\text { period }\end{array}$ & $\begin{array}{l}\text { No. of } \\
\text { traps }\end{array}$ \\
\hline $\begin{array}{l}\text { Codling moth, } \\
\text { CM }\end{array}$ & Cydia pomonella & 9 & Red delta & Apple & $\begin{array}{l}\text { Hawke’s Bay } \\
\text { Nelson }\end{array}$ & Jan-Feb & $\begin{array}{l}3 \\
3\end{array}$ \\
\hline $\begin{array}{l}\text { Lightbrown } \\
\text { apple moth, } \\
\text { LBAM }\end{array}$ & $\begin{array}{l}\text { Epiphyas } \\
\text { postvittana }\end{array}$ & 9 & Red delta & Apple & $\begin{array}{l}\text { Hawke’s Bay } \\
\text { Nelson }\end{array}$ & Jan-Mar & $\begin{array}{l}3 \\
3\end{array}$ \\
\hline $\begin{array}{l}\text { Oriental fruit } \\
\text { moth, OFM }\end{array}$ & $\begin{array}{l}\text { Grapholita } \\
\text { molesta }\end{array}$ & 6 & Red delta & Stonefruit & Hawke's Bay & Mar-Apr & 4 \\
\hline $\begin{array}{c}\text { Apple } \\
\text { leafcurling } \\
\text { midge, ALCM }\end{array}$ & Dasineura mali & 1.5 & Red delta & Apple & $\begin{array}{l}\text { Hawke’s Bay } \\
\text { Nelson }\end{array}$ & Jan-Feb & $\begin{array}{l}3 \\
3\end{array}$ \\
\hline $\begin{array}{l}\text { Citrophilous } \\
\text { mealybug, } \\
\text { Cmbug }\end{array}$ & $\begin{array}{l}\text { Pseudococcus } \\
\text { calceolariae }\end{array}$ & $<1$ & Red delta & Grape & $\begin{array}{l}\text { Hawke's Bay } \\
\text { Nelson }\end{array}$ & Feb-Mar & $\begin{array}{l}3 \\
3\end{array}$ \\
\hline $\begin{array}{l}\text { San José scale, } \\
\text { SJS }\end{array}$ & $\begin{array}{l}\text { Quadraspidiotus } \\
\text { perniciosus }\end{array}$ & $<1$ & $\begin{array}{l}\text { White } \\
\text { cardboard }\end{array}$ & Apple & Hawke's Bay & Feb-Mar & 4 \\
\hline $\begin{array}{l}\text { Froggatt's apple } \\
\text { leafhopper, FAL }\end{array}$ & $\begin{array}{c}\text { Edwardsiana } \\
\text { froggatti }\end{array}$ & 3 & $\begin{array}{l}\text { White \& yellow } \\
\text { cardboard, \& } \\
\text { yellow plastic }\end{array}$ & Apple & $\begin{array}{l}\text { Hawke’s Bay } \\
\text { Nelson }\end{array}$ & Feb-Mar & $\begin{array}{l}4 \\
4\end{array}$ \\
\hline $\begin{array}{l}\text { Australian crop } \\
\text { mirid, ACM }\end{array}$ & Sidnia kinbergi & 4 & $\begin{array}{c}\text { White \& yellow } \\
\text { cardboard \& } \\
\text { yellow plastic }\end{array}$ & Apple & $\begin{array}{l}\text { Hawke’s Bay } \\
\text { Nelson }\end{array}$ & Jan-Mar & $\begin{array}{l}4 \\
4\end{array}$ \\
\hline $\begin{array}{l}\text { Beneficial } \\
\text { species }\end{array}$ & Various & Various & $\begin{array}{l}\text { White \& yellow } \\
\text { cardboard \& } \\
\text { yellow plastic }\end{array}$ & Apple & $\begin{array}{l}\text { Hawke’s Bay } \\
\text { Nelson }\end{array}$ & Jan-Mar & $\begin{array}{l}4 \\
4\end{array}$ \\
\hline
\end{tabular}

were used without lures.

Yellow traps were also hung in the open, about $1.5 \mathrm{~m}$ above ground, amongst apple trees but were left for about 2 weeks. This was repeated approximately 6 weeks later to see if they attracted a different range of insects.

\section{Statistical analysis}

Paired sample t-tests $(\alpha=0.05)$ were used to compare catches on each adhesive type for each pest species and beneficial group for each trap type. Regional data were combined for this analysis, except for the comparison of the frequency of card changes. Insect counts from delta traps were compared directly, with no adjustment for the slightly different sized catching area on the PBA and HMPSA cards. The same applied to white traps because the two cards were made to be the same size. The two types of yellow trap were sufficiently different in size that the data needed to be standardised, so the counts were converted to numbers $/ 200 \mathrm{~cm}^{2}$.

\section{RESULTS}

Results of paired t-tests comparing numbers of each pest species and beneficial group on each type of adhesive are in an additional file available in the online version at https://journal.nzpps. org/index.php/nzpp.

\section{Delta traps}

Catches of five pest species on the two types of adhesive are compared in Figure 1. Similar numbers of CM, LBAM and OFM were caught 


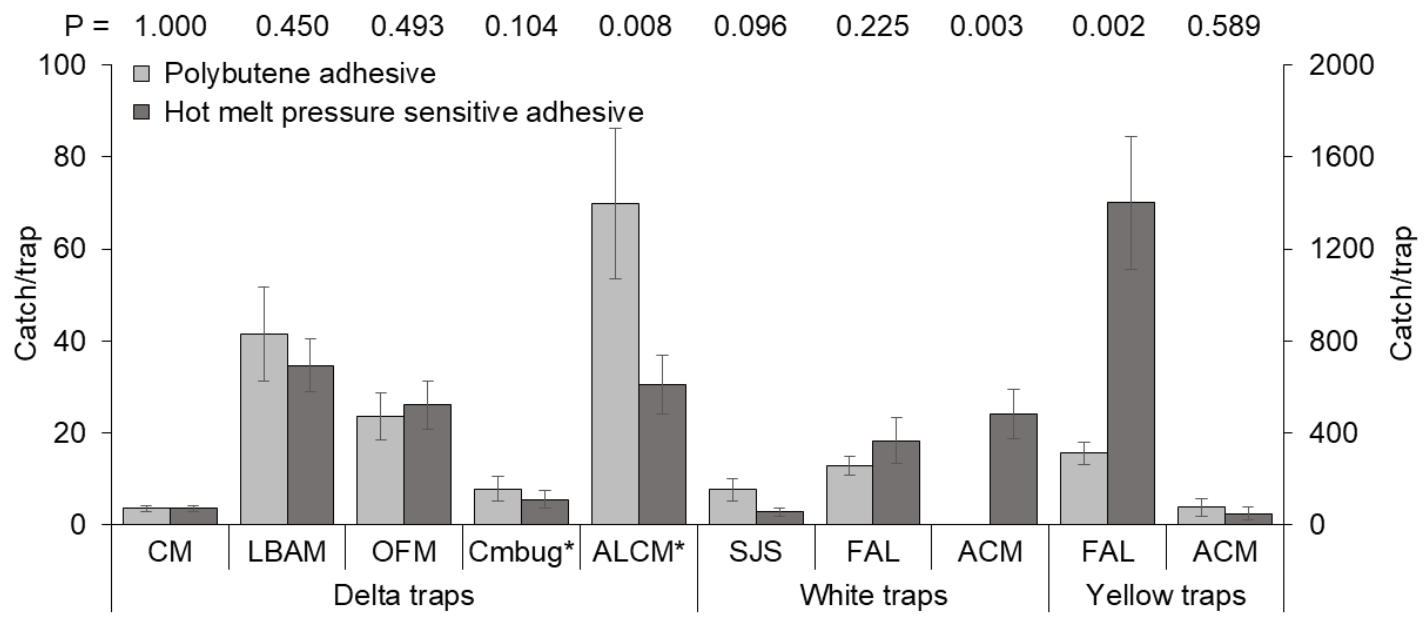

Figure 1 Mean \pm standard error (SE) number of eight insect pest species in delta, white or yellow traps with two types of adhesive. Traps were operated in Hawke's Bay and Nelson orchards and vineyards, for different periods from January to April 2019. Species: CM codling moth; LBAM lightbrown apple moth; OFM oriental fruit moth; Cmbug* Citrophilus mealybug; $\mathrm{ALCM}^{\star}$ apple leafcurling midge (* plotted on right hand axis); SJS San José scale; FAL Froggatt's apple leafhopper; and ACM Australian crop mirid. Results of paired sample t-tests are shown above the graph.

on both types of adhesive, but significantly more ALCM and citrophilous mealybug were caught using PBA than HMPSA. Some non-target insects were also trapped but these were not counted.

For the additional CM trial, similar numbers of CM were caught in Hawke's Bay traps on both types of adhesive irrespective of whether the adhesive cards had been changed weekly or left for the 4-week trial duration (Fig. 2). In Nelson, however, there was a difference in catches between these two treatments for HMPSA cards, but overall there was no difference in mean catches between the two card-change frequencies nor between the two types of adhesive.

\section{White cardboard traps}

The target species, SJS, was trapped in similar numbers on the PBA and HBPSA cards, although the former caught more at a $10 \%$ level of significance (Fig. 1). Numerous individuals of two other pest species (FAL and ACM) were also caught (Fig. 1). The type of adhesive did not affect the number of FAL captured, but more
ACM were trapped on HMPSA cards.

Fifteen species or groups of beneficial arthropods were recorded on the white traps during the 4-week exposure time. They were categorised as parasitoids, predators or pollinators. Six parasitoid wasps, five predators and one pollinator were commonly trapped. The parasitoids comprised Aphelinus mali, Platygaster demades, Anagrus spp., Encarsia spp. and Aphytis spp. These are natural enemies of woolly apple aphid (Eriosoma lanigerum), ALCM (Dasineura mali), leafhoppers, whitefly and scale insects, respectively. Mymarids, which are generalist egg parasitoids, were also trapped.

The most abundant predators were Ausejanus albisignatus(Miridae), whichattackALCMand the generalist Melanostoma fasciatum (small hoverfly, Syrphidae). The pollinators were predominantly a native bee Lasioglossum spp. (Halictidae), plus a few Apis mellifera (honey bee, Apidae). More predators and pollinators in total were caught on HMPSA than on PBA cards, but more of 5/6 parasitoids were caught using PBA (Fig. 3). 


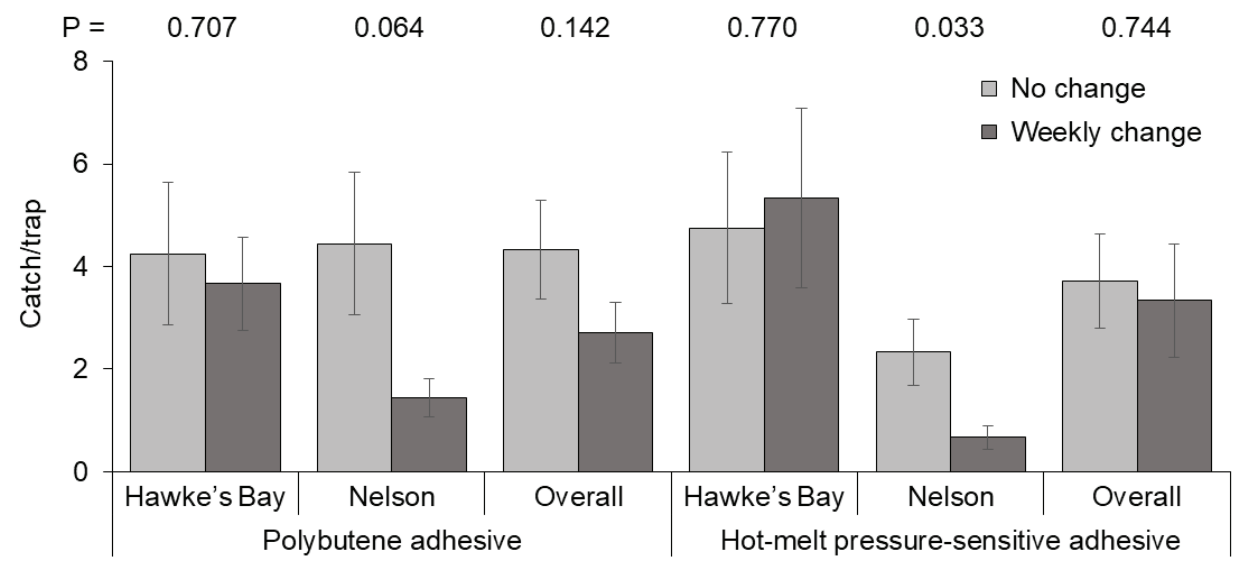

Figure 2 Mean $( \pm$ SE) number of codling moth in delta traps with two types of adhesive card, and the cards either not changed or changed weekly. Trials conducted over 4 weeks in Hawke's Bay and Nelson apple orchards, January to February 2019. Results of paired sample t-tests are shown above the graph.

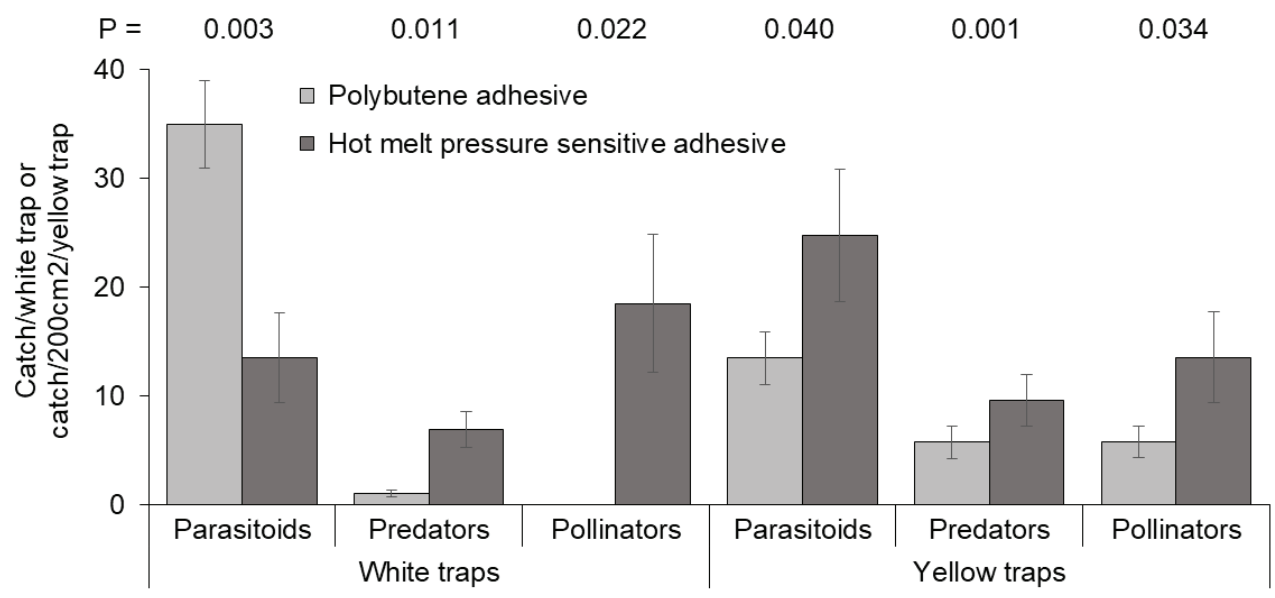

Figure 3 Mean $( \pm$ SE) number of beneficial species caught on white and yellow cardboard or plastic traps with two types of adhesive, (combined data from Hawke's Bay and Nelson orchards and vineyards), January to March 2019. Results of paired sample t-tests are shown above the graph.

\section{Yellow cardboard and plastic traps}

Amongst the pest insect species trapped on the un-baited yellow traps during over the two 2-week exposure times, significantly more FAL were caught using HMPSA than PBA, but the type of adhesive did not affect the number of ACM caught (Fig. 1). There were too few of the other pests found to compare their numbers.
The same species of parasitoids and pollinators, but a smaller range of predators, were recorded on the yellow traps than on the white traps and their numbers were lower (Fig. 3). HMPSA was the better surface for catching the native bee Lassioglossum spp. and parasitoids, except for $P$. demades (data not shown). The two most abundant predators ( $83 \%$ of total catches of 
this group) were Ausejanus albisignatus and the mite predator Stethorus bifidus (Coccinellidae). Numbers of both species on HMPSA cards were approximately twice as high as on PBA cards.

\section{DISCUSSION}

In general, irrespective of trap type, similar numbers or more of both pest and beneficial species were caught using HMPSA than with PBA. However, a distinction was apparent based on the size of the insects. HMPSA generally performed better for larger species $(>2 \mathrm{~mm}$ ), whereas PBA tended to be more effective for smaller insects.

The 'large' size category included the three main moth pests (CM, LBAM and OFM) and both types of glue were equally effective for these species. Based on this study, catches of CM and LBAM on the two adhesives were similar enough that spray thresholds developed with PBA cards should not need to be modified if using HMPSA cards. Furthermore, both types of adhesive were effective for up to 4 weeks, which indicated that the current practice of changing cards on a 3-weekly schedule can be retained. In the USA, Knight et al. (2019) found that the same two types of adhesive caught similar numbers of CM, but that HMPSA was better for OFM. White cardboard traps with HMPSA were also suitable for trapping FAL and mirids.

The remaining three pests targeted in this study, ALCM, SJS and citrophilous mealybug are all $<2 \mathrm{~mm}$ in size. More of these species were captured on PBA than on HMPSA cards, although the difference for SJS was significant only at the $10 \%$ level. In New Zealand, these species are currently monitored only for research purposes and no spray thresholds have been developed. If they were to be monitored with HMPSA cards, then thresholds may need to be specific for the type of card used.

The better performance of PBA for small insects also applied to parasitoids, but only on white card traps. The situation differed on yellow card traps where HMPSA was superior to PBA. Many insects including Hymenoptera have a strong attraction to yellow colours (Perez et al.
2012). The yellow card traps with PBA were a similar, but not identical, shade of colour to those with HMPSA and this may have influenced the greater attraction to the latter.

Amongst predators there were some exceptions to the generalisation that PBA was better for small insects. For example, S. bifidus is $\sim 1.2 \mathrm{~mm}$ and numbers on yellow traps were higher on HMPSA. The opposite occurred with Tasmanian lacewings (Micromus tasmaniae), which are about $8 \mathrm{~mm}$ long, while the various spiders trapped (all $>4 \mathrm{~mm}$ ) were caught in similar numbers on the two adhesives.

The reasons for the better trapping efficiency of PBA for smaller insects are unknown. The semi-liquid nature of PBA perhaps meant that a lesser pressure was enough for small insects to become entangled, whereas they may not have had enough mass to always get caught on the HMPSA surface.

One benefit of the PBA card is that it is a longestablished product that is widely used in many horticultural sectors. There are thoroughly tested spray thresholds accompanying monitoring programmes for CM and LBAM for these cards. However, compared with HMPSA, PBA has three important disadvantages. Firstly, the layer of glue is variable in terms of the quantity and coverage on each card. Secondly, the glue transfers onto everything that comes into contact with it. The cards are supplied folded in half and, when opened, glue invariably gets on hands and other surfaces. Thirdly, insects often become covered in adhesive which can make them difficult to identify and sex.

In this study, HMPSA proved to be effective for monitoring a range of pest and beneficial insects. The same AlphaScents cards have also been used to trap psyllids (Hall et al. 2010), fruit flies (Yee 2011) and moths (Roda et al. 2015, Knight et al. 2019), and they performed at least as well as PBA cards. The insects in these other studies were all larger than $3 \mathrm{~mm}$.

AlphaScents cards with HMPSA have several advantages over the Etec cards with PBA. Firstly, the HMPSA glue forms a thin, even layer that, unlike PBA, stays in place on the cards when 
touched. Secondly, the cards have an easily peeled paper covering and are printed with a grid that facilitates counting. Thirdly, the AlphaScents cards are made of cardboard, whereas the Etec cards are made of non-recyclable corflute plastic. Furthermore, the volume of the cardboard cards is approximately one-fifth that of the corflute cards. A change to AlphaScents cards would represent a considerable saving on landfill space for the over 100,000 cards used annually in the pipfruit sector. The main drawback of HMPSA was when it was used on white and yellow card traps as these had much larger by-catches (mainly various Diptera species), than the corresponding PBA card traps. This was not an issue inside delta traps with pheromone lures.

\section{CONCLUSIONS}

Compared with PBA, traps with HMPSA cards caught similar or greater numbers of the pest and beneficial species of interest, particularly those larger than $1.5 \mathrm{~mm}$. The HMPSA product has a much greater consistency and superior ease of use than the PBA cards that are currently deployed. For these reasons, it is recommended that the pipfruit industry switches to HMPSA cards for monitoring CM and LBAM.

The New Zealand apple export programme operates in a highly regulated environment. The monitoring of key species with pheromone traps is a crucial part of the pest management programme, and changing to HMPSA cards would represent a significant modification. Such a critical alteration should not be undertaken without much more extensive comparisons between the performances of both types of card, and whether treatment decisions would be affected by the trap catches.

\section{ACKNOWLEDGEMENTS}

This research was funded by The New Zealand Institute for Plant \& Food Research Limited. AlphaScents Inc. supplied the white and yellow HMPSA cards. Trial sites were provided by Bostock New Zealand, Johnny Appleseed Ltd and Mission Estate Winery in Hawke's Bay, and by Peckham's Cidery \& Orchard, Michael Moss and Richmond Plains Wines in Nelson. We thank our colleagues Lyn Cole, Anna Kokeny and Tara Taylor for technical support, John Charles who identified Sidnia kinbergi and Linley Jesson for statistical advice. The draft manuscript was reviewed and improved by Jim Walker, Tim Vandervoet, Pip Gerard, Ruth Falshaw and an anonymous referee.

\section{REFERENCES}

Anonymous 2018. New Zealand Apples \& Pears Incorporated Statistical Annual 2017. New Zealand Apples \& Pears Incorporated, Hastings, New Zealand. 28 p.

Eyles AC 1999. Introduced Mirinae of New Zealand (Hemiptera: Miridae). New Zealand Journal of Zoology 26: 355-372.

Hall DG, Sétamou M, Mizell RF 2010. A comparison of sticky traps for monitoring Asian citrus psyllid (Diaphorina citri Kuwayama). Crop Protection 29: 1341-1346.

Knight AL, Stewart W, Basoalto E 2019. Importance of trap liner adhesive selection for male moth catch (Lepidoptera: Tortricidae) with bisexual attractants. Journal of Applied Entomology 143: 95-104.

Perez J, Rojas JC, Montoya P, Liedo P, Gonzalez FJ, Castill A 2012. Size, shape and hue modulate attraction and landing responses of the braconid parasitoid Fopius arisanus to fruit odour-baited visual targets. Biocontrol 57: 405-414.

Roda AL, Brambila J, Barria J, Euceda X, Korytkowski C 2015. Efficiency of trapping systems for detecting Tuta absoluta (Lepidoptera: Gelechiidae). Journal of Economic Entomology 108: 2648-2654.

Walker JTS, Manktelow DWL, Wearing CH, Lo PL, Suckling DM 2001. Development of integrated fruit production programmes in the New Zealand horticultural industry. IOBC/WRPS Bulletin 24: 39-44.

Yee WL 2011. Evaluation of yellow rectangle traps coated with hot melt pressure sensitive adhesive and sticky gel against Rhagoletis indifferens (Diptera: Tephritidae). Journal of Economic Entomology 104: 909-919. 


\section{ADDITIONAL FILE 1}

\section{The effectiveness of two types of adhesive for catching insects in traps}

Peter L. Lo ${ }^{1, *}$, Roger Wallis ${ }^{2}$ and David E. Bellamy ${ }^{2}$

${ }^{1}$ The New Zealand Institute for Plant and Food Research Limited, Private Bag 1401, Havelock North, New Zealand

${ }^{2}$ The New Zealand Institute for Plant and Food Research Limited, 55 Old Mill Road, RD3, Motueka 7198, New Zealand

*Corresponding author: peter.lo@plantandfood.co.nz

Results of paired sample t-tests for various species and groups, comparing trap catches on polybutene adhesive and hot-melt pressure-sensitive adhesive.

\begin{tabular}{llcrc}
\hline Pest species or beneficial group & Trap & $\mathrm{t}$ & $\mathrm{df}$ & $\mathrm{P}$ \\
\hline Codling moth & Delta & 0.00 & 41 & 1.000 \\
Lightbrown apple moth & Delta & 0.96 & 17 & 0.350 \\
Oriental fruit moth & Delta & 0.70 & 14 & 0.493 \\
Citrophilous mealybug & Delta & 2.89 & 11 & 0.015 \\
Apple leafcurling midge & Delta & 3.49 & 8 & 0.008 \\
San José scale & White card & 1.92 & 7 & 0.096 \\
Froggatt's apple leafhopper & Yellow card & 3.87 & 15 & 0.002 \\
& White card & 1.33 & 7 & 0.225 \\
Australian crop mirid & Yellow card & 0.55 & 15 & 0.589 \\
\multirow{3}{*}{ Parasitoids } & White card & 4.50 & 7 & 0.003 \\
& White card & 4.33 & 7 & 0.003 \\
Predators & Yellow card & 2.25 & 15 & 0.040 \\
& White card & 3.44 & 7 & 0.011 \\
Pollinators & Yellow card & 3.92 & 15 & 0.001 \\
& White card & 2.93 & 7 & 0.022 \\
\hline
\end{tabular}

